\title{
Solar modulation of Northern Hemisphere winter blocking
}

\author{
David Barriopedro, ${ }^{1,2,3}$ Ricardo García-Herrera, ${ }^{2}$ and Radan Huth ${ }^{4}$ \\ Received 4 January 2008; revised 12 March 2008; accepted 19 March 2008; published 23 July 2008.
}

[1] The blocking response to the 11-year solar cycle is investigated for 44 winters

(1955-1999) and stratified according to the level of solar activity and the phase of the

Quasi-Biennial Oscillation (QBO). Several blocking features are modulated by solar activity, irrespective of the QBO phase, but the responses amplify under the QBO-west phases. Solar activity modulates the preferred locations for blocking occurrence over both Oceans, causing local frequency responses therein. Over the Pacific Ocean high/low solar activity induces an enhanced blocking activity over its eastern/western part. Atlantic blocking occurrence increases for both (high/low) solar phases, with a spatial dependent response confined to western/eastern Atlantic. Although solar effects are negligible in blocking frequency for the entire Atlantic sector, other blocking features exhibit significant responses. Low solar Atlantic blocking episodes last longer, are located further east and become more intense than high solar blocking events. The implications of these solar-related changes are discussed. Our results suggest that the excessively cold conditions recorded in Europe during the Maunder Minimum may have arisen from an eastward shift of long-lasting blockings with near-normal frequencies.

Citation: Barriopedro, D., R. García-Herrera, and R. Huth (2008), Solar modulation of Northern Hemisphere winter blocking, J. Geophys. Res., 113, D14118, doi:10.1029/2008JD009789.

\section{Introduction}

[2] Variations in solar radiation have a wide range of temporal scales, the most important one at interannualinterdecadal timescales being the 11-year solar cycle. Observational and modeling studies with General Circulation Models (GCMs) have reported a solar influence in several tropospheric fields, including surface temperatures, geopotential height, sea level pressure or the position of the low pressure centers [Christoforou and Hameed, 1997; van Loon and Shea, 1999; Gleisner and Thejll, 2003; Coughlin and Tung, 2004; Balling and Roy, 2005; Gleisner et al., 2005].

[3] In the last years, there has been a renewed interest in estimating solar effects in regional and global modes of tropospheric circulation variability [Kodera, 2002, 2003; Ruzmaikin and Feynman, 2002; Gimeno et al., 2003; Ogi et al., 2003; Bochniček and Hejda, 2005; Huth et al., 2007]. Kodera [2002, 2003] found that the winter North Atlantic Oscillation (NAO) is confined to the tropospheric Atlantic sector during low solar activity (LS), while it has a hemispherical structure (resembling the Northern Annual Mode (NAM)) and extends into the stratosphere during high solar activity (HS). Huth et al. [2006] found that not only the NAO, but the rest of the leading modes of variability

\footnotetext{
${ }^{1}$ CGUL, IDL, Faculdade de Ciências, Lisbon, Portugal.

${ }^{2}$ Departamento de Física de la Tierra II, Facultad de Ciencias Físicas, Universidad Complutense de Madrid, Madrid, Spain.

${ }^{3}$ Departamento de Física, Facultad de Ciencias, Universidad de Extremadura, Badajoz, Spain.

${ }^{4}$ Department of Climatology, Institute of Atmospheric Physics, Praha, Czech Republic.
}

Copyright 2008 by the American Geophysical Union. 0148-0227/08/2008JD009789\$09.00 show a tendency to be more zonal, their teleconnections spanning longer distances, and their action centers occupying larger areas under HS.

[4] The increasing evidence of solar effects in the troposphere suggests the existence of a potential mechanism to amplify and propagate the solar signal from the tropical stratosphere to the extratropical troposphere. Recent studies have reported detectable stratospheric responses to small changes in solar radiation, via a radiative-photochemical (UV-ozone) mechanism [e.g., Haigh, 1994; Hood, 1997; Shindell et al., 1999; Lean and Rind, 2001]. The solar signal in the troposphere has been explained in terms of a poleward propagation of the tropical stratospheric zonal wind anomalies and a subsequent extratropical downward propagation [Kodera et al., 1990; Kodera and Kuroda, 2002; Baldwin and Dunkerton, 2005; Matthes et al., 2006]. The nature of such pathway implies that other mechanisms, such as the Quasi-Biennial Oscillation (QBO) may interfere as modulating factors of the solar effects [Labitzke, 1987, 2005; Labitzke and van Loon, 1988; Soukharev and Hood, 2001]. Different studies have suggested that solar effects in the Northern Hemisphere $(\mathrm{NH})$ are usually stronger and more significant when winters are stratified according to the QBO phase [van Loon and Labitzke, 1988; Barnston and Livezey, 1989; Venne and Dartt, 1990; Bochniček et al., 2001].

[5] In particular, under LS and the QBO-west phase, the zonal flow weakens between Scandinavia and Greenland [Venne and Dartt, 1990; Bochniček and Hejda, 2006]. These patterns are usually associated with the occurrence of blockings, namely, quasi-stationary and persistent anticyclonic systems with a strong meridional component that interrupts the normal zonal flow [e.g., Rex, 1950]. Several 


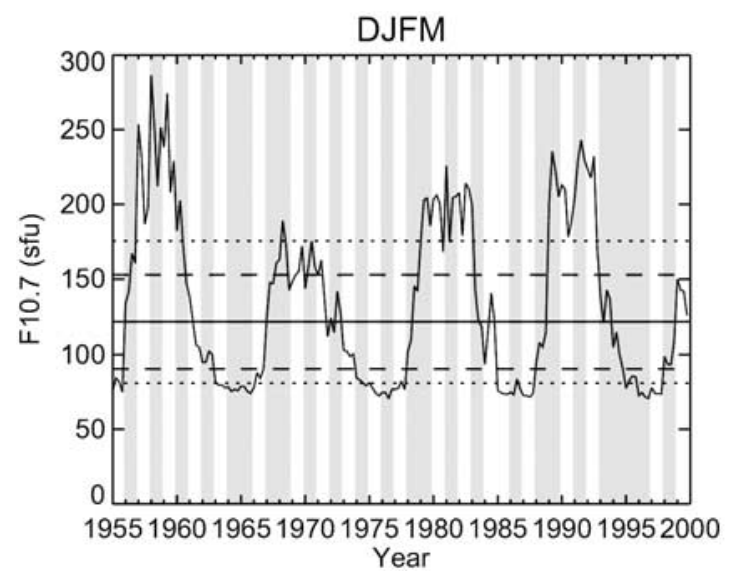

Figure 1. Time series of solar activity winter months (from December to March) and the definition of the solar and QBO stratifications. Solid, dashed, and dotted horizontal lines define, respectively, the median, upper/lower terciles, and upper/lower quartiles. Shaded areas in grey (white) indicate those winter months with an average DJFM westerly (easterly) QBO.

blocking features are widely credited, namely, a marked seasonal cycle with maximum occurrence in winter and spring, long persistence and a tendency to occur over the eastern basin of Atlantic and Pacific Oceans [e.g., Rex, 1950; Lejenäs and Økland, 1983; Barriopedro et al., 2006]. Since blocking episodes can persist for several weeks, they are associated with significant anomalies in temperature and precipitation over large areas. Under blocking occurrence, the mean eastward progression of extratropical synoptic disturbances is suppressed, leading to meridional shifts in the location of the storm tracks to the north and south of the blocking anticyclone. Furthermore, those regions upstream (downstream) of the blocking high experience warm (cold) conditions due to the air advection by the anomalous meridional flow [e.g., Carrera et al., 2004; Trigo et al., 2004]. Recently, blocking episodes have also been related with extreme episodes such as heat waves [Trigo et al., 2005] and droughts [García-Herrera et al., 2007].

[6] The idea of a solar signal in blocking activity is not new. Earlier studies suggested a near 11-year oscillation period in the frequency of winter $\mathrm{NH}$ blocking occurrence [Elliot and Smith, 1949]. However, no further investigations have been conducted to assess and quantify the blocking response. The objective of this study is to evaluate the solar modulation of different blocking features, including frequency of occurrence, persistence and preferred locations. The paper is organized as follows: the data and methods are described in the next section. Section three is devoted to the main results. Some implications are discussed in section four. Finally, conclusions are outlined.

\section{Data and Methods}

[7] Wolf sunspot numbers and the $10.7 \mathrm{~cm}$ radio flux have been employed to document atmospheric responses to the 11-year solar cycle (see references above). Although both variables show good agreement for the instrumental period, large differences have been reported between historical records of the former, due to inherent uncertainties derived from subjective estimates of sunspots and the lack of a quantitative physical dependence on solar irradiance [Vaquero, 2007]. Here, monthly data of the $10.7 \mathrm{~cm}$ radio flux are used from the National Geophysical Data Center of the NOAA (www.ngdc.noaa.gov/stp/SOLAR/ftpsolarradio. $\mathrm{html}$ ). The analyzed period includes 44 winters spanning between 1955 and 1999, which means four complete solar cycles. Since blocking activity peaks in winter and early spring, winter is defined in its extended version (DecemberJanuary-February-March). Solar activity is then stratified into three equal-sized parts according to the terciles of its winter distribution. Winters above (below) the upper (lower) tercile of solar activity are referred to as HS (LS). Other solar stratifications (i.e., the median and the quartile distributions) have also been tested to infer whether blocking responses depend on the level of solar activity. However, the results are qualitatively similar to the tercile stratification, the blocking response increasing when the HS/LS definition becomes more extreme. For the sake of simplicity, the results reported here will mainly refer to the tercile stratification.

[8] In addition, winters are stratified according to the QBO phase, defined as the averaged equatorial zonal mean zonal wind between $50 \mathrm{hPa}$ and $40 \mathrm{hPa}$ [Labitzke et al., 2002]. Those winters when the mean DJFM QBO remained positive (negative) are referred to as QBO-west (QBO-east) or westerly (easterly) QBO phase. Such stratification provides an almost balanced number of opposite QBO phases. Four sets of winters are then defined (Figure 1), depending on the solar activity level and the QBO-phase: HS and QBO-west, HS and QBO-east, LS and QBO-west and LS and QBO-east. Their sample sizes are shown in Table 1.

[9] On the other hand, a new automated detection method designed by Barriopedro et al. [2006] is used to identify blocking occurrence over the NH from daily $500 \mathrm{hPa}$ geopotential height fields of the NCEP/NCAR reanalysis [Kalnay et al., 1996]. This algorithm is based on the standard zonal index of Tibaldi and Molteni [1990]. The method identifies meridional flow reversals fulfilling minimum $\left(12.5^{\circ}\right)$ longitudinal extension and (5-day) persistence criteria. However, some new developments which take into account the 2-D spatial structure and temporal evolution of daily blocks are incorporated in order to better capture blocking episodes. The data set provides information on blocking occurrence, duration of blocking events and the daily evolution of other flow-related parameters as its location, intensity and extension over four different sectors: Atlantic $\left(-90^{\circ} \mathrm{W}, 0^{\circ}\right)(\mathrm{ATL})$, Europe $(0,90)^{\circ} \mathrm{E}$ (EUR), West Pacific $(90,180)^{\circ} \mathrm{E}(\mathrm{WPA})$ and East Pacific $(180,270)^{\circ} \mathrm{E}$ (EPA).

Table 1. Number of HS and LS Winters for Different Data Stratifications ${ }^{\mathrm{a}}$

\begin{tabular}{ccc}
\hline Solar Stratification & HS & LS \\
\hline Median & $22(13 / 9)$ & $22(11 / 11)$ \\
Terciles & $15(8 / 7)$ & $14(7 / 7)$ \\
Quartiles & $11(5 / 6)$ & $11(5 / 6)$ \\
\hline
\end{tabular}

${ }^{a}$ Numbers in brackets indicate those winters with a westerly/easterly QBO phase. 


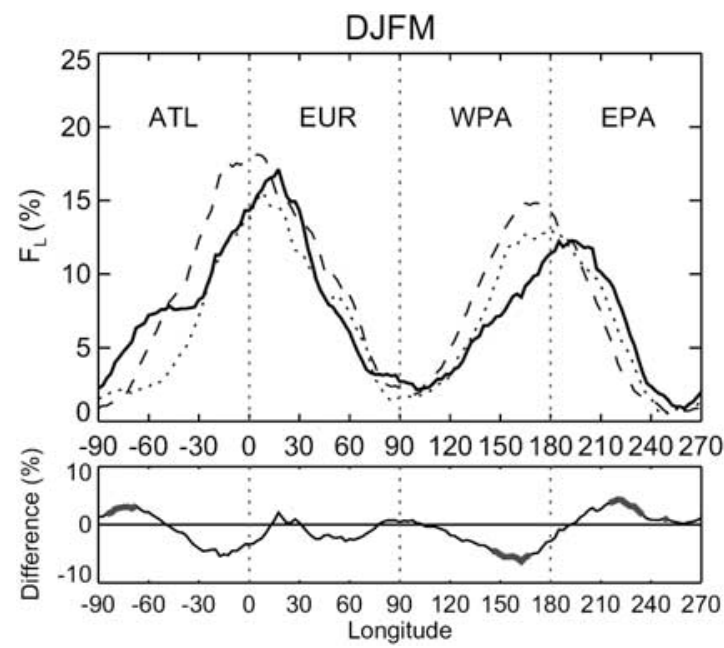

Figure 2. Blocking activity response to the solar cycle. Frequency composites of blocked days as a function of the longitude for HS (solid line), LS (dashed line) and mean solar activity (dotted line). $\mathrm{F}_{\mathrm{L}}$ indicates the frequency of days (relative to the total number of winter days) when a block was present over a given longitude. The bottom graphic displays frequency differences between HS and LS with thick gray lines indicating significant differences at the $\mathrm{p}<0.1$ level. Vertical dotted lines define the blocking sectors.

[10] Finally, monthly NAO values have been obtained from the Climatic Prediction Center (CPC) of the NOAA (http://www.cpc.ncep.noaa.gov). The NAO index is derived from a rotated principal component analysis (RPCA) applied to monthly mean standardized $500 \mathrm{hPa}$ height anomalies over $(20,90)^{\circ} \mathrm{N}$.

[11] Blocking responses to solar activity are first examined, irrespective of the QBO phase. In the second stage, the QBO modulation of the solar effects is considered. Winter composite analyses of blocking parameters are performed for HS and LS periods (with or without the QBO effect). Regional blocking patterns and impacts are also assessed by compositing daily atmospheric fields on a $2.5^{\circ} \times 2.5^{\circ}$ grid over the $\mathrm{NH}$ obtained from the NCEP/NCAR reanalysis [Kalnay et al., 1996]. The statistical significance has been estimated with a two-tailed t-test (null hypothesis of equal means).

\section{Results}

\subsection{Northern Hemisphere Blocking Activity}

[12] First, we examine the solar modulation of local blocking frequency for the whole NH. Figure 2 shows the 1-D spatial distribution of blocking activity, measured as the number of days when a given longitude was blocked by the presence of a blocking event lasting at least $5 \mathrm{~d}$. The frequency of blocked longitudes is expressed as the percentage of DJFM days (121 d, so $5 \%$ is roughly $4 \mathrm{~d}$ ). Maximum changes are observed over both Oceans. Blocking is enhanced/reduced over the western/eastern part of the Pacific Ocean for LS, this pattern being reversed (but to a lower extent) during HS winters. The enhancement of blocking occurrence over the eastern Pacific in HS corre- sponds well to an eastward shrinkage of the Pacific North American pattern (PNA), related especially to an eastward shift of its Aleutian center [Huth et al., 2006]. HS/LS composites over the Atlantic sector of Figure 2 are associated with nonhomogeneous increases of blocking activity (an increase of blocking activity over its midwestern/mideastern part during HS/LS). As a consequence, solar-related effects are not restricted to either HS or LS, but they arise from the influence of both solar phases. A longitudinal seasaw is detected over both Oceans when computing differences between HS minus LS composites (Figure 2, bottom) with a decrease/increase in western/eastern Pacific, the opposite being true in western/eastern Atlantic. These changes are only marginally significant (i.e., confined to certain longitudes) and they obey to nonlinear responses to solar activity.

[13] In terms of the blocking sectors defined by Barriopedro et al. [2006] (see section 2), net changes are expected in regional blocking activity (i.e., considering each blocking sector as a whole). Over EPA/WPA there is an increase/decrease during HS, since the date line is defined as the border between them. On the other hand, EuroAtlantic blocking sectors do not show a remarkable solar signal. EUR blocking seems to be unaffected by solar activity, while the ATL sector experiences opposite intrasectorial responses, leading to compensation when the whole sector is considered. When a t-test between HS and LS is performed for the regional frequency of blocking days (i.e., number of days when a blocking episode was detected over a given blocking sector) none of the four blocking sectors (nor the whole $\mathrm{NH}$ ) reach significant differences at $\mathrm{p}<0.1$ (even when solar effects are statistically significant at particular longitudes). These results suggest that solar activity has significant localized impacts in blocking frequency, which can alter the climatologically preferred locations for blocking occurrence without impinging the regional blocking sector frequency.

\subsection{QBO Modulation}

[14] Next, we examine the spatio-temporal evolution of blocking activity including the QBO-phase stratification. The results reported in the last section are not significantly altered when solar activity is stratified by the QBO-east phase. However, blocking responses become more evident if solar influence is analyzed under the westerly QBO phase. This is in agreement with previous studies, which revealed that solar effects regardless of the QBO modulation resemble those obtained for the QBO-east phases [Brown and John, 1979; Tinsley, 1988; Bochníček et al., 2001].

[15] Figure 3 shows the time-longitude Hovmöller diagram with the monthly frequency of blocked longitudes for HS and LS composites at the time of the QBO-west phase. The above reported differences are reproduced here through most of the winter, but they are stronger in mid to late winter (February-March), when blocking activity reaches its winter maximum, than in early winter (DecemberJanuary). For the Atlantic sector, a peak of blocking occurrence appears under HS centered at $60^{\circ} \mathrm{W}$ between January and March, which is absent in the LS composite (the lobe of maximum blocking activity over western Atlantic is also missing during QBO-east phases). In addition, LS situations show a preference for blocking activity 
a)

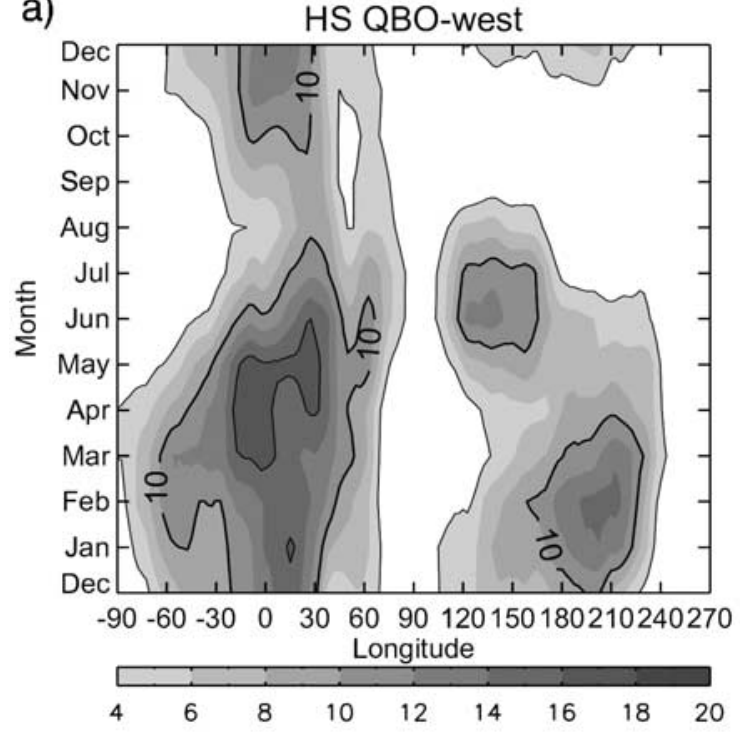

b)

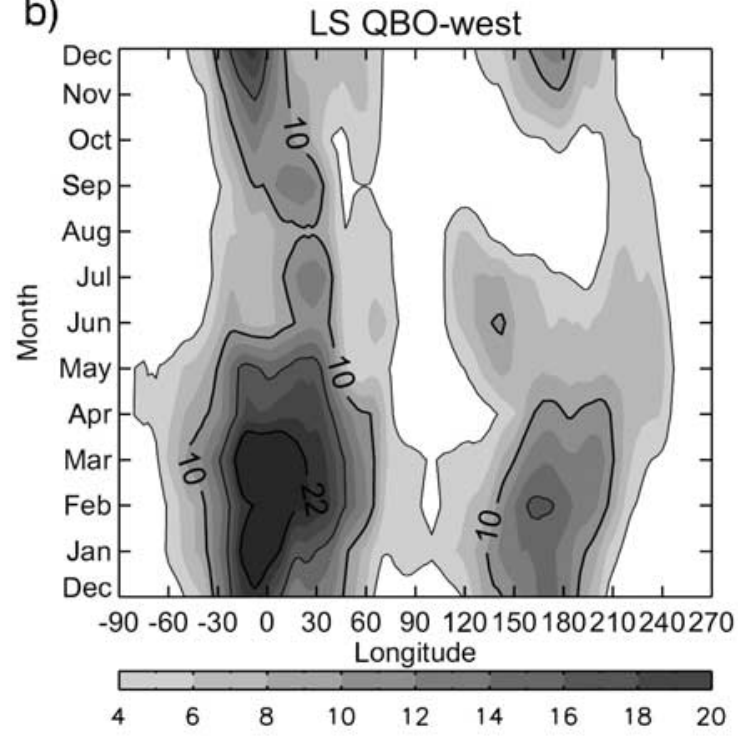

Figure 3. QBO-modulated solar signal in the spatiotemporal distribution of blocking activity. Longitude-time Hovmöller diagrams displaying the monthly blocking frequency (in percentage of its number of days) for: (a) HS and the QBO-west phase; (b) LS and the QBO-west phase. Only the activity levels above $4 \%$ are indicated. Shaded areas (solid lines) indicate contour intervals every $2 \%$ (4\%).

to occur near the Greenwich meridian. An enhancement of EUR blocking activity is also detected during LS and the QBO-west phase.

[16] The strengthening of the solar effects under QBO-west phases is supported by a number of facts: (1) the time of maximum responses (in mid to late winter) is in agreement with the mechanisms of the solar and QBO signal propagation to the extratropical troposphere reported in observational [e.g., Thompson et al., 2002; Baldwin and Dunkerton, 2005; Kodera and Kuroda, 2005] and modeling [Calvo et al., 2007] studies; (2) the amplification of differences between LS and HS under QBO-west, and only minimal solar impact under QBO-east, were also described by Tinsley [1988] for the position of storm tracks, Bochnićek et al. [1999] for the dominant patterns of winter pressure systems in the lower troposphere (Aleutian and Icelandic lows) and Bochnićek et al. [2001] for the zonality of circulation in the Euro-Atlantic area; (3) blocking responses are stable in terms of the solar stratification (i.e., the effects are similar when HS/LS is stratified according to the median, tercile or quartile division), suggesting a robust signal and a real physical mechanism behind these results.

[17] In order to provide further evidence of the QBO modulation in the Atlantic sector, composites of the blocking action centers for HS and LS and QBO-west phases have been computed. Figure 4 shows a latitude-longitude plot of the daily blocking center frequency, each blocking center represented by an open circle (grey/black for HS/LS). The circle size is proportional to the number of daily blocks detected over each specific grid point. In addition, the latitudinal and longitudinal distributions of the number of block centers are plotted with solid/dashed lines, respectively (the frequency expressed as the percentage of the total number of blocks in each composite). The observed changes in the spatial frequency distribution of blocking under different solar activity are reflected in the preferred locations of their action centers. Under HS, winter blocks span from eastern North America to eastern Atlantic, with two local maxima near central and eastern Atlantic. Under LS, the density of blocks over western and central Atlantic is suppressed almost to zero and action centers are strongly confined to the eastern Atlantic basin. Latitudinal differences are not very noticeable, apart from a LS tendency to shift southward the latitudinal maximum of blocking occurrence.

\subsection{Atlantic Blocking Response}

[18] Up to now, we have found that NH blocking activity is not highly sensitive to the solar signal, the strongest impacts being detected over both Oceans. The differences in blocking activity seem to arise from a solar modulation of the preferred blocking locations, which amplifies during the QBO-west phases.

[19] Aside from blocking activity, the most characteristic feature of blocking is its persistence. A comparative analysis of NH blocking duration reveals more persistent blocking events in LS winters (significant at $p<0.05$ ). By breaking down the whole NH into the four preferred blocking sectors, a significant response in blocking persistence is only detected in the Atlantic sector. Since most of the solar signal in NH blocking persistence arises from Atlantic blockings, from now on, we will focus on the Atlantic sector. For the sake of simplicity, the term "blocking" will refer to "Atlantic blocking" and the QBO effect will be excluded because significant differences are attained regardless of the QBO modulation.

[20] Blocking events are on average about three $\mathrm{d}$ more persistent in LS ( $\sim 13$ days) than in HS ( $\sim 10$ days) winters (which means about a 30\% increase). Although these results do not look very impressive, they become clearer when 


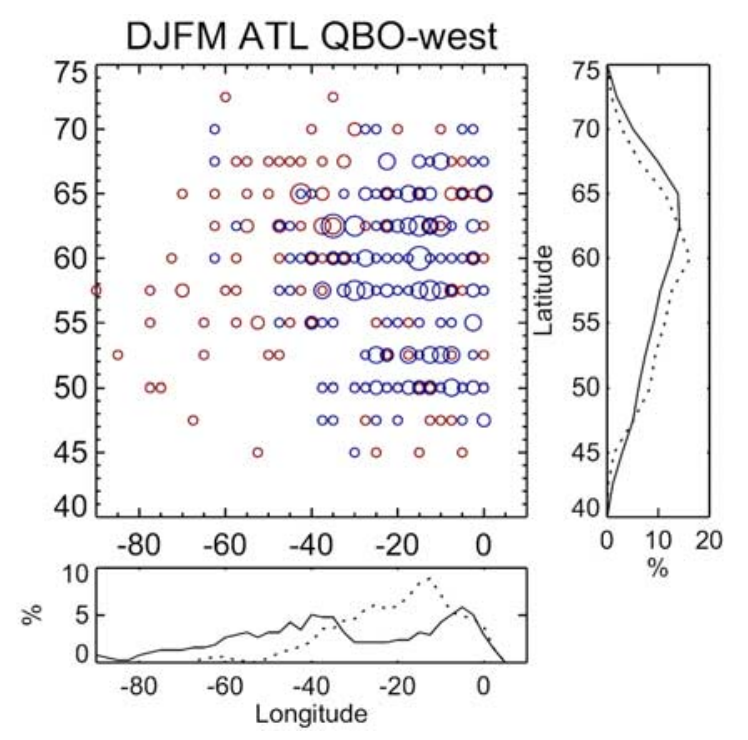

Figure 4. QBO-modulated solar effects in the location of blocking centers. 2-D (longitude-latitude) distribution of daily blocks occurring under the QBO-west phase and HS (red circles) and LS (blue circles). The size of the circle is proportional to the frequency of block occurrence (the smallest ones indicating just one day). The bottom graphic (on the right) represents the longitudinal (latitudinal) normalized (to 100\%) density distribution of blocking centers for HS (solid line) and LS (dashed line).

blockings are grouped according to their duration. Figure 5 shows the relative mean contribution of blocking episodes with different durations (ranged in intervals of 5 days) to the total number of blocking events (100\%) for HS (dark shaded bars) and LS (light shaded bars). Short-lived blocking events are relatively more frequent for HS than for LS, while the contribution of long-lasting blocks is larger for LS than for HS. As a consequence, extremely persistent blocking episodes (longer than 15 days) are more prone to occur during LS. The increased persistence of blockings in LS implies a less vigorous zonal circulation, and is therefore consistent with a weakened zonality of circulation over the Euro-Atlantic area [e.g., Bochniček et al., 2001; Huth et al., 2006, 2007].

[21] In addition to the opposite intrasectorial changes in blocking frequency reported above, the dissimilar balance between short and long-lasting blocking episodes can also explain the lack of significant differences in the frequency of blocking days. Since more than $50 \%$ of blocking episodes have longevities of 5-10 days, the strongest contribution to the blocking days frequency comes from short-lived block episodes. Thus the higher density of longlasting blocking events in LS winters compensates for the higher concentration of short-lived blocking episodes in HS, leading to small frequency changes (note that 3 blocking events of 5 days duration are equivalent to 1 episode of 15 days in terms of the frequency of blocking days).

[22] The cumulative histogram of Figure 6a shows the number of blocking events with durations equal or higher than a given threshold for HS and LS composites (the same criteria holds regarding shaded areas). For a better comparison, the number of blocking episodes of a given bin is normalized by the total number of events recorded in its composite (thus, the frequency of blocking events with durations equal or longer than $5 \mathrm{~d}$ fits to $100 \%$ ). Both composites show the typical decreasing long-tail blocking distribution [e.g., Lejenäs and Økland, 1983; D'Andrea et al., 1998; Wiedenmann et al., 2002], dashed lines indicating an exponential fit. Focusing on blocking episodes up to $15-$ 20 days, the longer the blocking longevity the higher the difference becomes. Maximum differences are reached for durations of about 15 days. Beyond that limit (which may suffer from sampling problems) blocking distributions tend to converge. As a consequence, when solar activity is high, blocking durations exhibit a shorter-tail pattern than during LS.

[23] It is frequently argued that the exponential shape of the blocking duration distribution is a common and unique feature of this phenomenon [e.g., Dole and Gordon, 1983; Pelly and Hoskins, 2003]. This argument is usually put in context to show that the responsible mechanisms of blocking formation and maintenance exhibit the distribution of a Markovian process. When this distribution is plotted in a log-plot, the exponential curve appears linear, the slope of the linear regression being interpreted as a characteristic temporal scale of blocking. This analysis (Figure 6b) reveals different blocking time-scales depending on the level of solar activity. For HS the well-known temporal scale of about 4-5 days is obtained. However, the characteristic temporal scale of LS blockings is longer, suggesting that LS blocking has a more persistent nature. These results are observed regardless of the QBO modulation and they are also detectable (but to a lower extent) over other blocking sectors (especially EUR) (figures not shown).

[24] Up to now, it has been shown that ATL blockings possess a different range of typical durations and preferred

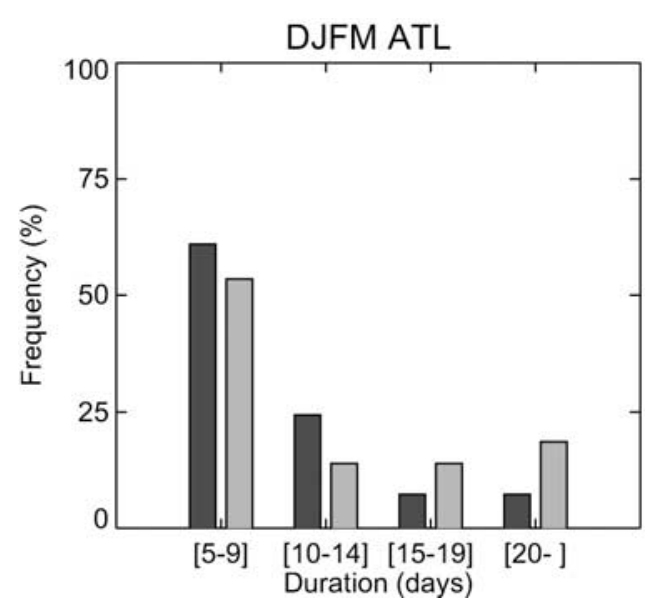

Figure 5. Solar impact on blocking persistence. Normalized histogram distributions of ATL blocking episode durations for HS (dark bars) and LS (light bars). Bars represent the relative contribution of blocking episodes within 5-day duration intervals (starting at 5 days) to the total frequency of blocking episodes for each composite. (i.e [5-9] means the percentage of blocking episodes with durations between 5 and 9; [20-] refers to as blocking events with durations equal or longer than 20 days.) 
a)

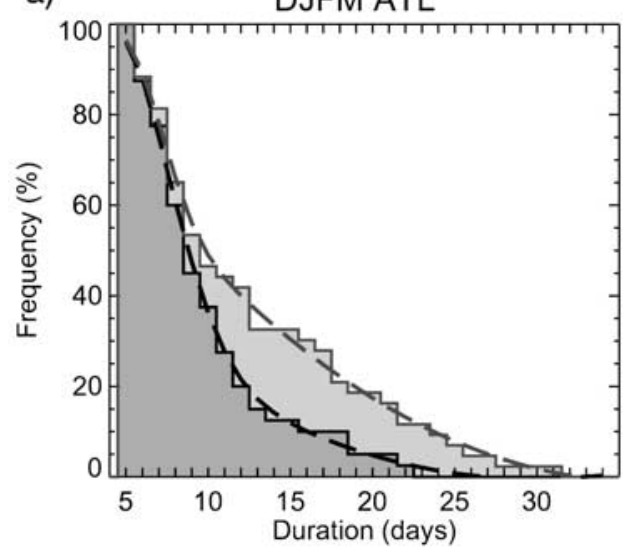

b)

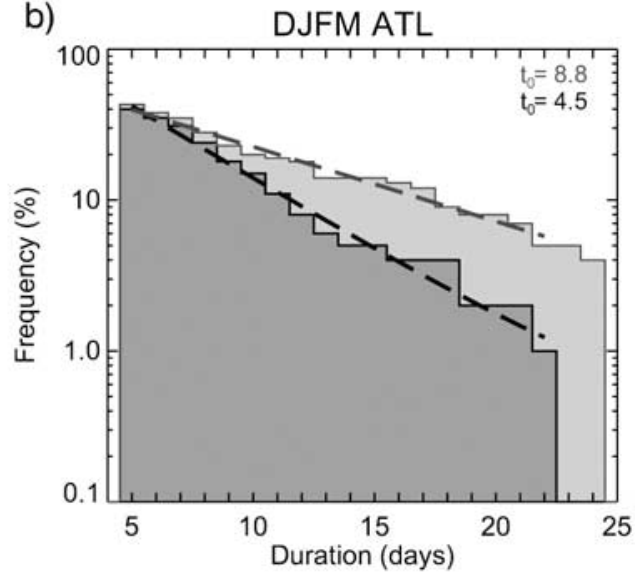

Figure 6. Solar modulation of the characteristic blocking time-scales. (a) Normalized distribution of ATL blocking events with durations equal or higher than given, dark (light) shaded bars representing the composites for HS (LS). Dashed lines indicate an exponential fit. (b) Same as Figure 6a but in a logarithmic-scale plot. $\mathrm{t}_{0}$ values on the upper right-hand corner display the slope of the regression for HS (dark) and LS (light) distributions.

regions of occurrence under the solar cycle modulation. These regional changes in ATL blocking are expected to impinge on the characteristic spatial patterns of blocking, and hence, on their impacts. The so-called blocking patterns are computed by compositing the $500 \mathrm{hPa}$ geopotential anomalies for those days when a block is identified over a given sector. They are a useful tool of blocking diagnosis, providing information about the characteristic synoptic pattern associated with regional blocking occurrence and the location and intensity of their action centers [e.g., D'Andrea et al., 1998]. Figure 7 shows the composites of daily $500 \mathrm{hPa}$ geopotential heights and 2-m surface temperature anomalies for blocking occurrence under HS and LS. Daily anomalies have been computed as the departures from the daily climatology (1955-1999), the number of days used for the composite analysis being 467 and 367 for HS and LS, respectively. Both composites show the wellknown dipole structure of positive anomalies around $60^{\circ} \mathrm{N}$ and negative anomalies near $40^{\circ} \mathrm{N}$ [Trigo et al., 2004]. The former reflects the anticyclonic circulation of the block; the latter is symptomatic of an enhancement of storm-tracks, due to the southward shift of extratropical disturbances induced by the block action. In spite of these shared features, blocking patterns show a significant structural change in response to solar activity. For HS winters, the positive center of the blocking pattern is located over south Greenland and span over a great part of the Atlantic Ocean. The associated negative center encompasses the whole Atlantic Ocean, being evident from North America to central Europe. Under LS, the blocking pattern intensifies and it is spatially confined to mideastern Atlantic. The blocking center loads over Iceland, while the opposite anomaly center locates west of Iberia, penetrating further into the European continent and then curving north. The intensification of the blocking pattern under LS can be regarded as a result of both: (1) the spatial concentration of blockings over eastern Atlantic (Figure 4); (2) the relative longer durations of blocking events, since more persistent blocks are associated with stronger anomalies (i.e., more intense blockings) [Wiedenmann et al., 2002; Diao et al., 2006].

[25] Differences in the blocking patterns also bring different impacts. Under LS, Europe experiences very cold temperatures and warm temperatures are detected in south Greenland and the Labrador Sea (Figure 7b). This dipole of temperature anomalies is associated with the strong meridional circulation of the block, advecting southerly/northerly warm/cold air upstream/downstream of the blocking center [Trigo et al., 2004]. When solar activity is high, blocks move westward and weaken (i.e., the meridional circulation is less pronounced). As a consequence, the downstream circulation of the block does not impinge so dramatically over Europe, cold air advections are reduced, and the extension and intensity of the negative temperature anomalies weaken (Figure 7a).

[26] Since the split of the blocking activity is more pronounced when the QBO modulation is considered (see Figure 4), the patterns of Figure 7 also amplify for the westerly QBO phase. These results are in agreement with Venne and Dartt [1990] and Bochnićek and Hejda [2006] who reported a weakening of the zonal westerlies into Europe and an increased poleward/equatorward circulation over the North Atlantic Ocean/central Europe under solar minimum conditions and the QBO-west phase winters.

[27] As Atlantic blocks are strongly linked with the negative phase of the winter NAO [Shabbar et al., 2001; Scherrer et al., 2006; Barriopedro et al., 2006; CrociMaspoli et al., 2007], the patterns of Figure 7 resemble those obtained by Kodera [2002, 2003] and Huth et al. [2006] for the winter NAO. The fact that the blocking patterns spread over larger distances in HS is in line with a larger geographical extent of the NAO signal [Kodera, 2002, 2003; Huth et al., 2006]. Regardless of which phenomenon leads to which (NAO leads blocking [e.g., Shabbar et al., 2001] or blocking leads NAO [e.g., CrociMaspoli et al., 2007]), it is interesting to assess to what degree blocking activity is affected by the change in the NAO pattern (i.e., whether the linkage blocking-NAO is 
a)

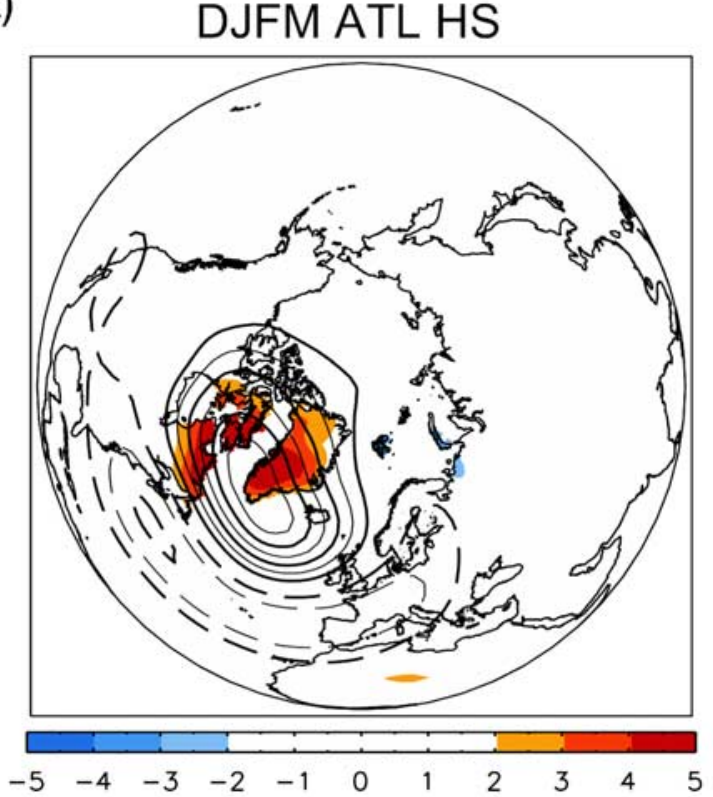

b)

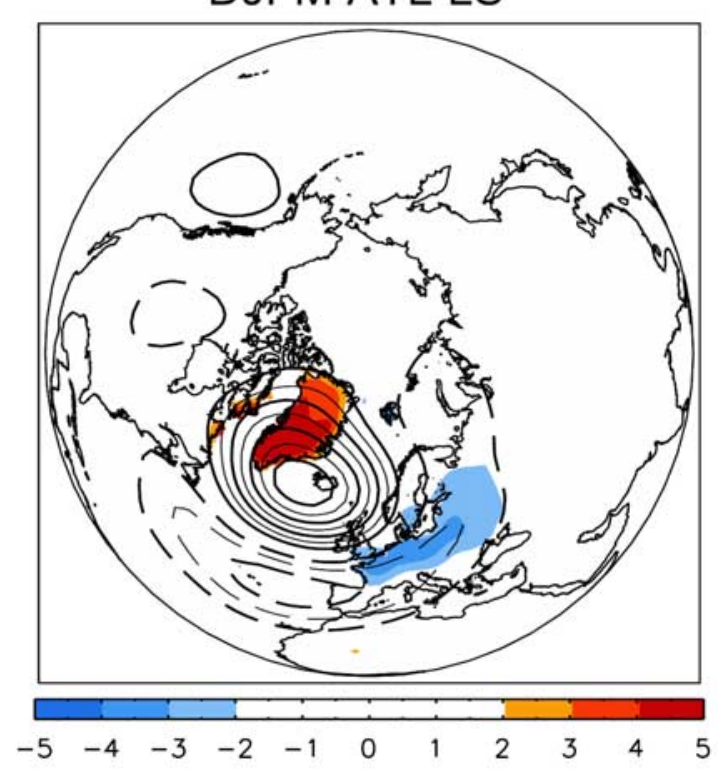

Figure 7. Solar effects in blocking patterns and associated impacts. Winter composites of daily $500 \mathrm{hPa}$ geopotential height (lines) and 2-m temperature (shaded areas) anomalies for Atlantic blocking days under: (a) HS and (b) LS. Solid (dashed) lines indicate positive (negative) height anomalies with contour intervals of $50 \mathrm{gpm}$ starting at $50(-50) \mathrm{gpm}$. Positive (negative) 2-m temperatures are red (blue) shaded with $1{ }^{\circ} \mathrm{C}$ contour interval starting at $2(-2){ }^{\circ} \mathrm{C}$

modulated by solar activity). In order to provide an estimate, linear regression between the normalized frequency of blocking days and the NAO has been performed for the full data set and HS and LS winters. To maximize the sample size, monthly values belonging to each set of winters have been used. Figure 8 shows the linear regressions for the quartile stratification. The relationship strengthens and the fit errors are lower under HS.
[28] Solar-related differences in the NAO-blocking relationship may be attributed to a number of factors: (1) several studies have reported a more penetrating downward propagation of stratospheric zonal wind anomalies into the troposphere and a strong stratospheric-tropospheric coupling during HS, these mechanisms being able to explain the zonally extended pattern of the NAO and its extension into the stratosphere [Kodera and Kuroda, 2005]. In addition, it is argued that the essence of blocking is located in the upper troposphere, so suggesting a stratospheric influence [Pelly and Hoskins, 2003; Schwierz et al., 2004]. As a consequence, both phenomena may share a common source of perturbations under HS, so becoming strongly coupled. This result is supported by the fact that blocking activity is also significantly correlated with the Arctic Oscillation (AO) (which provides a measure of the polar vortex) during HS only (figure not shown); (2) another hypothesis can be drawn from the results of Huth et al. [2006]. They reported a NAO tendency to split in two independent modes under HS: the original NAO shifted to the west and a wave train centered over the Mediterranean. If the NAO pattern during LS periods is regarded as the superposition of these two modes (the NAO basic state for HS and the Mediterranean pattern), then the explained blocking variance may be reduced by the loss of the NAO identity. The westward shift of the Atlantic blocking pattern in HS gives further support to the realism of the split of the NAO in HS detected by Huth et al. [2006]. Whichever the responsible mechanism is, it should be stated that the strengthening of the blocking-NAO linkage for the HS only becomes remarkably evident for the quartile solar stratification, so the results may be suffering from sampling problems.

\section{Discussion: The Role of Blocking During the Late Maunder Minimum}

[29] The sequence of arguments presented in the previous sections may be of paramount importance to throw light on the role of blocking during past climatic conditions of anomalous solar activity. Among them, the Maunder Minimum (MM, 1645-1715) represents the coldest period of the Little Ice Age (LIA, 1300-1900), an interval of reduced solar activity [e.g., Eddy, 1976]. Within the MM, the Late Maunder Minimum (LMM, 1675-1715) was a period of persistent extremely cold winters in Europe [e.g., Luterbacher et al., 2001].

[30] It has been suggested that the wintertime cooling over Europe during the LMM might be attributed to the combination of external forcing factors (solar irradiance and volcanic activity) and internal oscillations in the North Atlantic (including a reduced zonal flow circulation over the eastern North Atlantic) [Luterbacher et al., 2001, 2004; Shindell et al., 2003]. Koslowski and Glaser [1999] estimated the frequency of weak westerly flow events (i.e., "blockings") over the North Atlantic during the LIA, based upon a Western Baltic severity ice index. They found strong phases of increased ice from 1655 to 1710 , suggesting that periods with predominantly blocking situations were frequent in the LMM. Moreover, synoptical comparisons with current conditions have shown that LMM winters were characterized by significant higher pressures over northern Europe [Luterbacher et al., 2001] and below normal pres- 

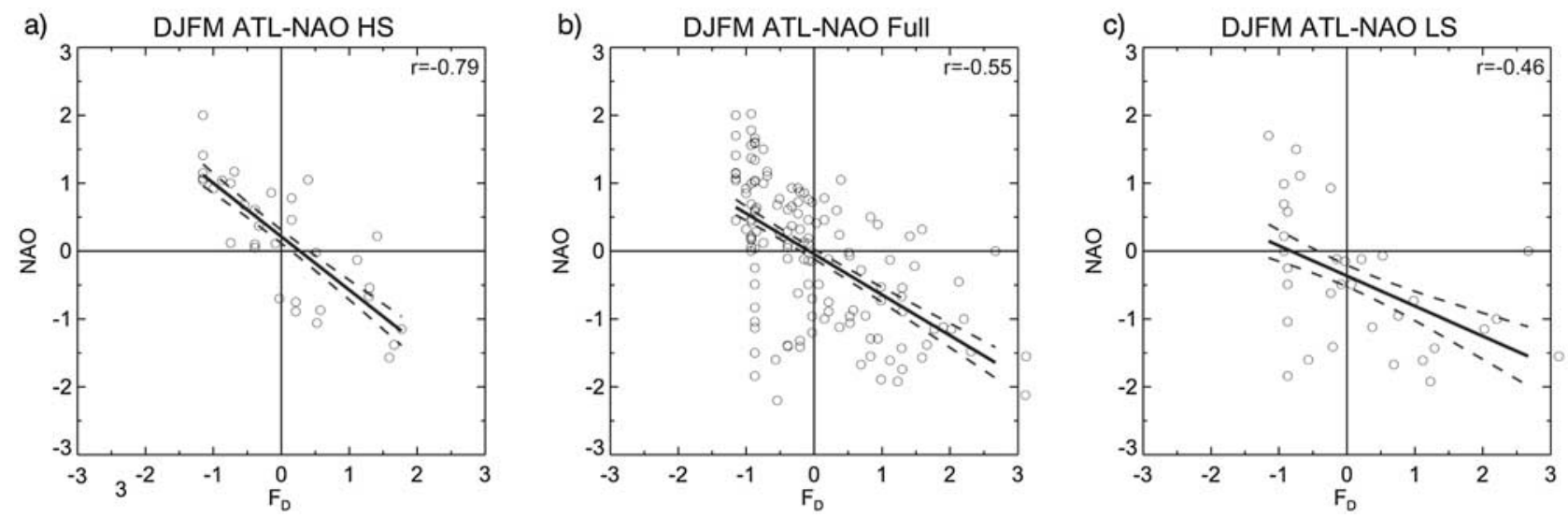

Figure 8. Solar signal in the NAO-blocking relationship. Linear regressions between the winter monthly values of NAO and the normalized frequency of Atlantic blocking days ( $\left.F_{D}\right)$ for: (a) HS, (b) full data, and (c) LS. Solid (dashed) lines indicate the regressed field (fit-error estimate). Every pair of values is represented by an open circle. The Pearson correlation coefficient is displayed in the upper right corner. The quartile solar stratification is used.

sures over the Mediterranean [Xoplaki et al., 2001], which are symptomatic of blocking patterns aloft [Trigo et al., 2004]. By using multiproxy data, Wanner et al. [1995] also found that the LMM was characterized by strong sea level pressure reversals over Northwestern Europe and large outbreaks of northeasterly cold continental air. Casty et al. [2005] identified recurrent winter climate regimes from reconstructed and modeled data, reporting a period of about 30 years (1670 to 1700 ) with pronounced positive values of blocking-related regimes over western Europe.

[31] Apart from these blocking proxies, there is no evidence supporting whether differences in blocking regimes between HS and LS are able to explain the cold weather conditions that affected Europe during the LMM.

a)

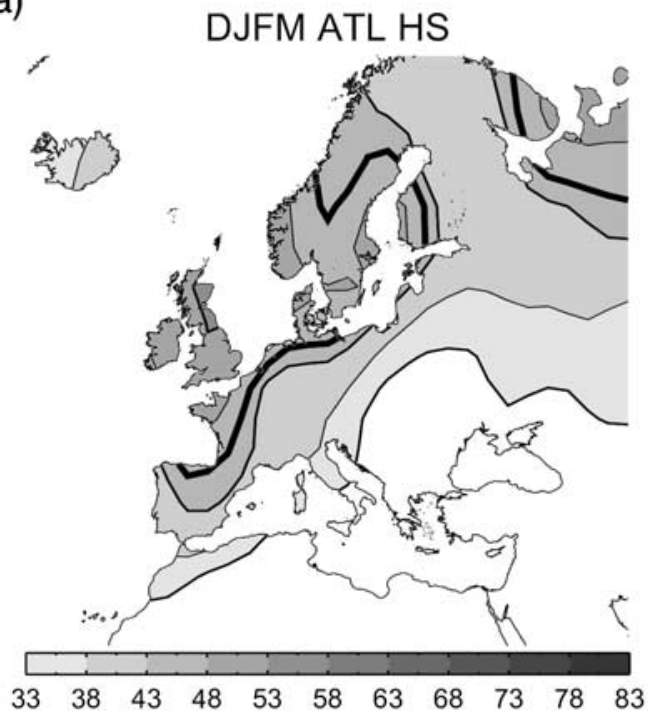

The lack of such an observational study is surprising given: (1) the vast amount of literature suggesting a decisive role of Atlantic blocking in the extremely cold temperatures recorded in Europe during the LMM (see references above); (2) the observational fact that Atlantic blocking patterns are important modulating factors of the ice production [Koslowski and Glaser, 1999] and snow cover conditions [Garcia-Herrera and Barriopedro, 2006] over northern Europe.

[32] Here, the distributions of daily $2 \mathrm{~m}$ temperature during ATL blocking occurrence are compared with their climatological distributions in order to determine if cold temperatures are more likely to occur during the HS or LS. Daily $2 \mathrm{~m}$ temperature anomalies are computed by remov-

b)

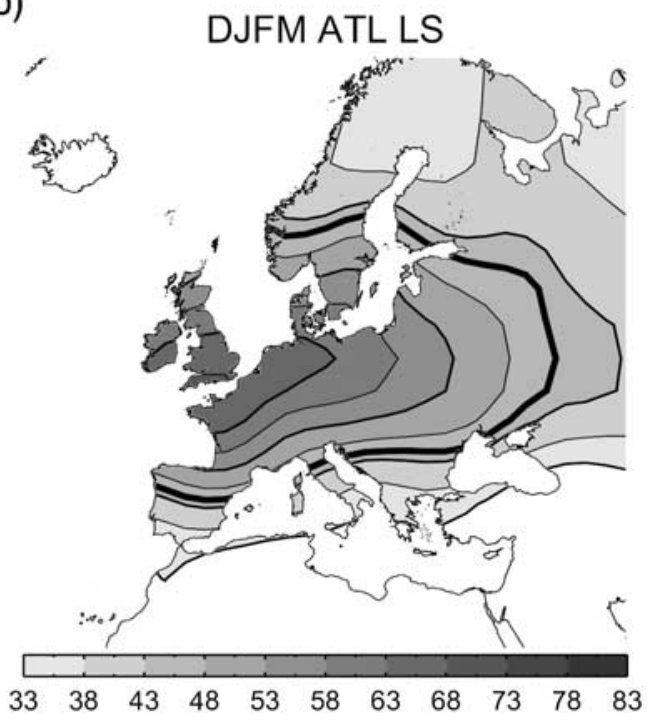

Figure 9. Solar modulation of the blocking impacts in the temperature distribution. Percentage of Atlantic blocking days with daily mean 2-m temperature anomalies in the lower tercile of its winter distribution under: (a) HS and (b) LS. Solid lines and shaded areas denote those values exceeding the expected value $(33.3 \%)$ with $5 \%$ contour interval. The thick solid line denotes the $95 \%$ confidence threshold based upon a binomial test. The quartile solar stratification is used. 
ing the climatological daily values for the 1955-1999 period. The percentage of blocking days with temperature anomalies in the lower tercile is computed (Figure 9). To estimate the local statistical significance of the departures from the expected value $(33.3 \%)$ a binomial test is applied (95\% confidence level). The occurrence of winter ATL blocking reveals a significant shift in the daily mean surface temperature distributions toward colder temperatures over most of Europe. However, ATL blocking regimes under HS and LS lead to different regional impacts. The effects of LS blocking spread over most of Europe, with more than $50 \%$ of the blocking days having temperature anomalies in the lower tercile. This percentage significantly drops for HS, only exceeding the expected value over northwestern Europe. As a consequence, cold European events are more likely to occur under LS blocking regimes.

[33] The shift toward colder daily mean surface temperatures during winter blocking is also accompanied by a shift in the tails of the distribution toward more extreme cold days, defined as the 10th percentile (not shown). However, the fraction of LS blocking days associated with extreme cold temperatures is significant over the northwestern portion of Europe, whereas extreme cold days during HS are not significantly related with blocking occurrence. It is interesting to note that these results are observed whether or not the number of blocking days in a given solar phase is higher than in another. Thus the solar-induced change in the structural pattern of the blocking regime is enough by itself to explain why Europe experiences colder conditions in LS than in HS. These findings support the hypothesis that blocking may have been partially responsible for the European cooling during the LMM through a change in the preferred blocking locations rather than a significant increase in the frequency of blocking occurrence.

[34] Summarizing, several key processes may have met in LMM regarding blocking: (1) the eastward shift and high spatial confinement of preferred blocking regions; (2) the relatively greater persistence for blocking events, which, in turn, are associated with more intense action centers, and, hence, stronger cold air advections over northern Europe; (3) recurrent negative winter NAO values (i.e., more frequent blocking) in agreement with the reconstructions of Luterbacher et al. [2000]. Note, however, that the second process does not necessarily preclude the third, since more long-lasting blocking events can coexist with fewer shortlived blocking episodes. In addition, our results do not show significant increases in blocking frequency under LS. Thus on the basis of the results presented here, the cold pattern that dominates northern Europe during LS conditions (such as the LMM) is mainly attributed to eastward-shifted long persistent Atlantic blocking events (two first mechanisms) rather than to anomalous high blocking recurrence. The latter situation seems to be of secondary importance, but it could be a supporting factor, since more frequent NAO negative values would contribute to amplify the patterns reported before.

\section{Conclusions}

[35] This paper explores the blocking response to the 11-year solar cycle by analyzing 44 winters stratified according to the level of solar activity and the phase of the QBO.
The present analysis of blockings provides a new angle of the view of the solar effects on tropospheric circulation. The main conclusions can be summarized as follows.

[36] 1. As a whole, NH blocking frequency is not affected by the level of solar activity, although blocking persistence increases when the solar activity is low. The lack of a global blocking activity response is explained by a solar modulation of the preferred blocking locations over both Oceans without regional frequency changes. Regionally, blocking activity exhibits different responses to the solar cycle over the Atlantic and Pacific Oceans. Over the Pacific, the solar effects manifest as an increase/decrease (decrease/increase) of blocking frequency over its eastern/western side during HS (LS), whereas Atlantic blocking occurrence enhances for both (HS/LS) phases, but with a spatial dependent response (confined to western/eastern Atlantic). These solar signals are detectable for all solar stratifications (from the median to the quartiles stratification) but they are marginally (i.e., locally) significant, being amplified when the QBO-west phase is considered only.

[37] 2. Atlantic blocking episodes exhibit the strongest solar signals. Variations in spatial extent and position of action centers are appreciable for all solar activity stratifications, regardless of the QBO modulation. HS is connected with extensive blocking locations, less persistent blocks and a more zonally extended blocking pattern. LS blocking episodes are longer-lasting and located further east. As a consequence, the LS blocking pattern evolves over the eastern Atlantic and the loading centers intensify, thus amplifying the surface atmospheric impacts.

[38] 3. ATL blocking occurrence enhances the likelihood of cold days over Europe under either HS or LS. However, cold surface temperature anomalies are more prone to occur during blocking episodes of LS, whereas winter HS blocking does not significantly alter the distribution of cold temperatures. These results support the hypothesis that blocking may have played a significant role in the extremely cold weather conditions that dominated Europe during the LMM. However, contrary to previous studies, which partially attributed these anomalous patterns to an excessively frequent blocking action, it is found that the cold pattern may have arisen from an eastward shift of long-lasting blockings with unchanged frequencies as a consequence of the dominant type of eastern Atlantic blocking events during low solar activity periods.

[39] Acknowledgments. The authors would like to thank to Juerg Luterbacher, who provided useful comments and suggestions. D. B. and R. G. H. were supported by the Spanish Science and Technology Department through the VALIMOD (Climatic Validation of Conceptual Models) project (REN2002-04558-C04-01). R. H. was supported by the Grant Agency of the Czech Academy of Sciences, projects A3042401 and A300420805. Three anonymous reviewers provided helpful comments, which improved the original manuscript.

\section{References}

Baldwin, M. P., and T. J. Dunkerton (2005), The solar cycle and stratosphere-troposphere dynamical coupling, J. Atmos. Sol. Terr. Phys., 67, $71-82$.

Balling, R. C., Jr., and S. S. Roy (2005), Analysis of spatial patterns underlying the linkage between solar irradiance and near surface temperatures, Geophys. Res. Lett., 32, L11702, doi:10.1029/2005GL022444.

Barnston, A. G., and R. E. Livezey (1989), A closer look at the effect of the 11-year solar cycle and the quasi-biennial oscillation on Northern Hemisphere $700 \mathrm{mb}$ height and extratropical North American surface temperature, J. Clim., 2, 1295-1313. 
Barriopedro, D., R. Garcia-Herrera, A. R. Lupo, and E. Hernández (2006), A climatology of Northern Hemisphere blocking, J. Clim., 19, $1042-$ 1063.

Bochníček, J., and P. Hejda (2005), The winter NAO pattern changes in association with solar and geomagnetic activity, J. Atmos. Sol. Terr Phys., 67, 17-32.

Bochníček, J., and P. Hejda (2006), Connections between the distribution of prevailing winds in the winter Northern Hemisphere, solar/geomagnetic activity and the QBO phase, Stud. Geophys. Geod., 50, 299-318.

Bochníček, J., P. Hejda, and J. Pýcha (1999), The effect of geomagnetic and solar activity on the distribution of controlling pressure formations in the Northern Hemisphere in winter, Stud. Geophys. Geod., 43, 390-398.

Bochníček, J., P. Hejda, and J. Pýcha (2001), Comparison of solar and geomagnetic activity effects on the Northern Hemisphere weather changes, Stud. Geophys. Geod., 45, 133-154.

Brown, G. M., and J. I. John (1979), Solar cycle influences in tropospheric circulation, J. Atmos. Sol. Terr. Phys., 41, 43-52.

Calvo, N., M. A. Giorgetta, and C. Peña-Ortiz (2007), Sensitivity of the boreal winter circulation in the middle atmosphere to the quasi-biennial oscillation in MAECHAM5 simulations, J. Geophys. Res., 112, D10124, doi:10.1029/2006JD007844

Carrera, M. L., R. W. Higgins, and V. E. Kousky (2004), Downstream weather impacts associated with atmospheric blocking over the northeast Pacific, J. Clim., 17, 4823-4839.

Casty, C., D. Handorf, C. C. Raible, J. F. González-Rouco, A. Weisheimer, E. Xoplaki, J. Luterbacher, K. Dethloff, and H. Wanner (2005), Recurrent climate winter regimes in reconstructed and modelled $500 \mathrm{hPa}$ geopotential height fields over the North Atlantic/European sector 1659-1990, Clim. Dyn., 24, 809, doi:10.1007/s00382-004-0496-8.

Christoforou, P., and S. Hameed (1997), Solar cycle and the Pacific "centers of action", Geophys. Res. Lett., 24, 293-296.

Coughlin, K., and K. K. Tung (2004), Eleven-year solar cycle signal throughout the lower atmosphere, J. Geophys. Res., 109, D21105, doi:10.1029/2004JD004873.

Croci-Maspoli, M., C. Schwierz, and H. C. Davies (2007), Atmospheric blocking: Space-time links to the NAO and PNA, Clim. Dyn., 29, 713-725, doi: $10.1007 / \mathrm{s} 00382-007-0259-4$.

D’Andrea, F., et al. (1998), Northern Hemisphere atmospheric blocking as simulated by 15 atmospheric general circulation models in the period 1979-1988, Clim. Dyn., 14, 385-407.

Diao, Y., J. Li, and D. Luo (2006), A new blocking index and its application: Blocking action in the northern hemisphere, J. Clim., 19, 4819-4839.

Dole, R. M., and N. D. Gordon (1983), Persistent anomalies of the extratropical northern hemisphere wintertime circulation: Geographical distribution and regional persistence characteristics, Mon. Weather Rev., 111, $1567-1586$

Eddy, J. A. (1976), The Maunder Minimum, Science, 192, 1189-1202.

Elliot, R. D., and T. B. Smith (1949), A study of the effect of large blocking highs on the general circulation in the northern hemisphere westerlies, J. Meteorol., 6, 67-85.

García-Herrera, R., and D. Barriopedro (2006), Northern hemisphere snow cover and atmospheric blocking variability, J. Geophys. Res., 111, D21104, doi:10.1029/2005JD006975.

García-Herrera, R., D. Paredes, R. M. Trigo, I. F. Trigo, E. Hernández, D. Barriopedro, and M. A. Mendes (2007), The outstanding 2004-2005 drought in the Iberian Peninsula: Impacts and atmospheric circulation associated, J. Hydrometeorol., 8, 483-498.

Gimeno, L., L. de la Torre, R. Nieto, R. García, E. Hernández, and P. Ribera (2003), Changes in the relationship NAO-Northern Hemisphere temperature due to solar activity, Earth Planet. Sci. Lett., 206(1-2), 15-20.

Gleisner, H., and P. Thejll (2003), Patterns of tropospheric response to solar variability, Geophys. Res. Lett., 30(13), 1711, doi:10.1029/2003GL017129.

Gleisner, H., P. Thejll, M. Stendel, E. Kaas, and B. Machenhauer (2005), Solar signals in tropospheric re-analysis data: Comparing NCEP/NCAR and ERA 40, J. Atmos. Sol. Terr. Phys., 67, 785-791.

Haigh, J. D. (1994), The role of stratospheric ozone in modulating the solar radiative forcing of climate, Nature, 370, 544-546.

Hood, L. L. (1997), The solar cycle variation of total ozone: Dynamical forcing in the lower stratosphere, J. Geophys. Res., 102, 1355-1370.

Huth, R., L. Pokorná, J. Bochníček, and P. Hejda (2006), Solar cycle effects on modes of low-frequency circulation variability, J. Geophys. Res., 111, D22107, doi:10.1029/2005JD006818.

Huth, R., J. Bochníček, and P. Hejda (2007), The 11-year solar cycle affects the intensity and annularity of the Arctic Oscillation, J. Atmos. Sol. Terr. Phys., 69, 1095-1109.

Kalnay, E., et al. (1996), The NCEP/NCAR 40-year reanalysis project, Bull. Am. Meteorol. Soc., 77, 437-471.

Kodera, K. (2002), Solar cycle modulation of the north Atlantic oscillation: Implication in the spatial structure of the NAO, Geophys. Res. Lett., 29(8), 1218, doi:10.1029/2001GL014557.
Kodera, K. (2003), Solar influence on the spatial structure of the NAO during the winter 1900-1999, Geophys. Res. Lett., 30(4), 1175, doi:10.1029/2002GL016584.

Kodera, K., and Y. Kuroda (2002), Dynamical response to the solar cycle, J. Geophys. Res., 107(D24), 4749, doi:10.1029/2002JD002224.

Kodera, K., and Y. Kuroda (2005), A possible mechanism of solar modulation of the spatial structure of the North Atlantic Oscillation, J. Geophys. Res., 110, D02111, doi:10.1029/2004JD005258.

Kodera, K., K. Yamazaki, M. Chiba, and K. Shibata (1990), Downward propagation of upper stratospheric mean zonal wind perturbation to the troposphere, Geophys. Res. Lett., 17, 1263-1266.

Koslowski, G., and R. Glaser (1999), Variations in Reconstructed Ice Winter Severity in the Western Baltic from 1501 to 1995 , and their Implications for the North Atlantic Oscillation, Clim. Change, 41, $175-191$

Labitzke, K. (1987), Sunspots, the QBO, and the stratospheric temperature in the north polar region, Geophys. Res. Lett., 14, 535-537.

Labitzke, K. (2005), On the solar cycle-QBO relationship: A summary, J. Atmos. Sol. Terr. Phys., 67, 45-54.

Labitzke, K., and H. van Loon (1988), Associations between the 11-year solar cycle, the $\mathrm{QBO}$ and the atmosphere part I: The troposphere and stratosphere in the northern hemisphere winter, J. Atmos. Sol. Terr. Phys., 50, 197-206.

Labitzke, K., et al. (2002), The Berlin Stratospheric Data Series [CDROM], Meteorol. Inst., Free Univ. Berlin, Berlin, Germany.

Lean, J., and D. Rind (2001), Earth's response to a variable Sun, Science, 292, 234-236.

Lejenäs, H., and H. Økland (1983), Characteristics of northern hemisphere blocking as determined from long time series of observational data, Tellus, 35A, 350-362.

Luterbacher, J., et al. (2000), Monthly mean pressure reconstruction for the Late Maunder Minimum Period (AD 1675-1715), Int. J. Climatol., 20, 1049-1066.

Luterbacher, J., R. Rickli, E. Xoplaki, C. Tinguely, C. Beck, C. Pfister, and H. Wanner (2001), The Late Maunder Minimum (1675-1715)-a key period for studying decadal scale climatic change in Europe, Clim. Change, 49, 441-462.

Luterbacher, J., D. Dietrich, E. Xoplaki, M. Grosjean, and H. Wanner (2004), European seasonal and annual temperature variability, trends, and extremes since 1500, Science, 303, 1499, doi:10.1126/science.1093877.

Matthes, K., Y. Kuroda, K. Kodera, and U. Langematz (2006), Transfer of the solar signal from the stratosphere to the troposphere: Northern winter, J. Geophys. Res., 111, D06108, doi:10.1029/2005JD006283.

Ogi, M., K. Yamazaki, and Y. Tachibana (2003), Solar cycle modulation of the seasonal linkage of the North Atlantic Oscillation (NAO), Geophys. Res. Lett., 30(22), 2170, doi:10.1029/2003GL018545.

Pelly, J., and B. Hoskins (2003), A new perspective on blocking, J. Atmos. Sci., 60, 743-755.

Rex, D. F. (1950), Blocking action in the middle troposphere and its effect upon regional climate. part II: The climatology of blocking action, Tellus, 2, 275-301

Ruzmaikin, A., and J. Feynman (2002), Solar influence on a major mode of atmospheric variability, J. Geophys. Res., 107(D14), 4209, doi:10.1029/ 2001JD001239.

Scherrer, S. C., M. Croci-Maspoli, C. Schwierz, and C. Appenzeller (2006), Two-dimensional indices of atmospheric blocking and their statistical relationship with winter climate patterns in the Euro-Atlantic region, Int. J. Climatol., 26, 233-249.

Schwierz, C., M. Croci-Maspoli, and H. C. Davies (2004), Perspicacious indicators of atmospheric blocking, Geophys. Res. Lett., 31, L06125, doi:10.1029/2003G1019341

Shabbar, A., J. Huang, and K. Higuchi (2001), The relationship between the wintertime North Atlantic Oscillation and blocking episodes in the North Atlantic, Int. J. Climatol., 21, 355-369.

Shindell, D., D. Rind, N. Balachandran, J. Lean, and P. Lonergan (1999), Solar cycle variability, ozone, and climate, Science, 284, 305-308.

Shindell, D. T., G. A. Schmidt, R. L. Miller, and M. E. Mann (2003), Volcanic and solar forcing of climate change during the preindustrial era, J. Clim., 16, 4094-4107.

Soukharev, B., and L. L. Hood (2001), Possible solar modulation of the equatorial quasi-biennial oscillation: Additional statistical evidence, J. Geophys. Res., 106, 14,855-14,868.

Thompson, D. W. J., M. P. Baldwin, and J. M. Wallace (2002), Stratospheric connection to Northern Hemisphere wintertime weather, Implications for Prediction, J. Clim., 15, 1421-1428.

Tibaldi, S., and F. Molteni (1990), On the operational predictability of blocking, Tellus, 42A, 343-365.

Tinsley, B. A. (1988), The solar cycle and the QBO influences on the latitude of storm tracks in the North Atlantic, Geophys. Res. Lett., 15, $409-412$ 
Trigo, R. M., I. F. Trigo, C. C. DaCamara, and T. J. Osborn (2004), Winter blocking episodes in the European-Atlantic sector: Climate impacts and associated physical mechanisms in the reanalysis, Clim. Dyn., 23, $17-28$.

Trigo, R. M., R. García-Herrera, J. Díaz, I. F. Trigo, and M. A. Valente (2005), How exceptional was the early August 2003 heatwave in France?, Geophys. Res. Lett., 32, L10701, doi:10.1029/2005GL022410.

van Loon, H., and K. Labitzke (1988), Association between the 11-year solar cycle, the QBO and the atmosphere. part II: Surface and $700 \mathrm{mb}$ in the Northern Hemisphere in winter, J. Clim., 1, 905-920.

van Loon, H., and D. J. Shea (1999), A probable signal of the 11-year solar cycle in the troposphere of the Northern Hemisphere, Geophys. Res. Lett., 26, 2893-2896.

Vaquero, J. M. (2007), Historical sunspot observations: A review, $A d v$. Space Res., 40, 929-941.

Venne, D. E., and D. G. Dartt (1990), An examination of possible solar cycle-QBO effects in the Northern Hemisphere troposphere, J. Clim., 3, $272-281$.

Wanner, H., C. Pfister, R. Brázdil, P. Frich, K. Frydendahl, T. Jónsson, J. Kington, S. Rosenørn, and E. Wishman (1995), Wintertime European
Circulation Patterns during the Late Maunder Minimum Cooling Period (1675-1704), Theor. Appl. Climatol., 51, 167-175.

Wiedenmann, J. M., A. R. Lupo, I. I. Mokhov, and E. A. Tikhonova (2002), The climatology of blocking anticyclones for the Northern and Southern hemispheres: Block intensity as a diagnostic, J. Clim., 15, 3459-3473.

Xoplaki, E., P. Maheras, and J. Luterbacher (2001), Variability of climate in meridional Balkans during the periods $1675-1715$ and $1780-1830$ and its impact on human life, Clim. Change, 48, 581-614.

D. Barriopedro, CGUL, IDL, Faculdade de Ciências, Campo Grande, Ed. C8, 1749-016 Lisbon, Portugal. (dbarriopedro@fc.ul.pt)

R. García-Herrera, Departamento de Física de la Tierra II, Facultad de Ciencias Físicas, Universidad Complutense de Madrid, Avda. Complutense, 28080 Madrid, Spain.

R. Huth, Department of Climatology, Institute of Atmospheric Physics, Boční II 1401, 14131 Praha 4, Czech Republic. 